\title{
TIME SERIES PROPERTIES OF THE GERMAN MONTHLY PRODUCTION INDEX
}

\author{
GEBHARD FLAIG
}

CESIFO WORKING PAPER NO. 833

CAtegory 5: Fiscal Policy, Macroeconomics and Growth

JANUARY 2003

\footnotetext{
An electronic version of the paper may be downloaded

- from the SSRN website: www.SSRN.com

- from the CESifo website: www.CESifo.de
} 


\title{
TIME SERIES PROPERTIES OF THE GERMAN MONTHLY PRODUCTION INDEX
}

\begin{abstract}
The production index is an important indicator for assessing the cyclical state of the economy. Unfortunately, the monthly time series is contaminated by many noisy components like seasonal variations, calendar and vacation effects. Only part of those nuisance components are explicitly considered in the seasonal adjustment procedures used by statistical agencies.

In this paper, we propose a more flexible specification for the seasonal and working day effects and introduce an indicator for the summer vacations effect. We allow for time-varying parameters and show that the resulting Unobserved Components Model delivers more reliable results for the adjusted series.
\end{abstract}

JEL Classification: C22, E32.

Keywords: production index, seasonal adjustment, working day effect, business cycles, unobserved components models.

Gebhard Flaig

Ifo Institute for Economic Research

Poschingerstrasse 5

81679 Munich

Germany

flaig@ifo.de 


\section{Introduction}

Despite the fact that industrial production contributes only about one fourth to German GDP, production indices play still a very important role in assessing the cyclical state of the economy. The main reason may be that in contrast to GDP data production indices are available on a monthly basis and are published with a shorter delay than data for the whole economy. The possible advantages of production indices come with some costs as they are characterised by a high degree of short-run noise due to seasonal fluctuations, the effects of vacations and public holidays as well as other calendar and weather effects. In order to extract a reliable measure of the components of interest, i.e., the trend and the cycle, we need a flexible model which can capture the possibly time-varying effects of the "nuisance"-components.

Most statistical agencies use a variant of the census-method in order to adjust production indices for seasonal and other intra-year fluctuations (for Germany see Jung, 2002, and Kirchner, 1999). Since the census-approach is not explicitly based on a specified time series model (see, e.g., Ladiray/Quenneville, 2000), it is rather difficult to incorporate certain aspects of the production index like month specific variances for random shocks or time-varying effects of the number of different days in a month.

In this study, we use an Unobserved Components (UC) Model for modelling a monthly German production index and decomposing it into the trend, cycle, seasonal, calendar and irregular components. As Harvey/Jaeger (1993) argue, this class of models provides a useful framework as they "are explicitly based on the stochastic properties of the data". They are based on interpretable and welldefined models for the individual components, are very flexible in accommodating peculiar features of the time series and can be scrutinised by rigorous tests.

The most novel aspect of this study is a more flexible specification of the shortrun components than is usually employed in the existing literature. We include an indicator for the effect of summer vacation and for the so called bridging days and allow the parameters to vary over time, the variances of the seasonal shocks to be different for different frequencies (trigonometric seasonal heteroscedasticity in the terminology of Koopman / Franses, 2001) and the variance of the irregular component to be different in different calendar months (seasonal heteroscedasticy). 
The organisation of the paper is as follows: In section 2, we present the econometric model and the specification of the unobserved components. Section 3 contains the empirical results for a long time series of the German production index from 1955 to 2001 . The final section contains a short summary and some concluding remarks.

\section{An Unobserved Components Model for the Production Index}

The basic assumption underlying Unobserved Components Models is that an observed time series $y_{t}$ can be decomposed into several interpretable components (for a general discussion see Harvey 1989; Maravall 1995). In the following, we decompose the logarithm of the monthly production series into the unobserved components trend $T$, cycle $C$, season $S$, the calendar effect $A$, and the irregu$\operatorname{lar} I$ :

(1) $y_{t}=T_{t}+C_{t}+S_{t}+A_{t}+I_{t}$.

The trend component represents the long-run development of production and is specified as a random walk with a possibly time-varying drift rate $\mu_{t}$ :

(2) $T_{t}=T_{t-1}+\mu_{t-1}+\varepsilon_{t}$.

The level impulse $\varepsilon_{t}$ is a white noise variable with mean zero and variance $\sigma_{\varepsilon}^{2}$.

The drift rate $\mu_{t}$ is allowed to vary over time and is also defined as a random walk:

(3) $\mu_{t}=\mu_{t-1}+\xi_{t}$.

The drift impulse $\xi_{t}$ is a white noise variable with variance $\sigma_{\xi}^{2}$.

The model specified in equations (2) and (3) implies that the trend component follows an IMA(2,1)-process. Special cases emerge when we set the variance of the shocks to zero. If both are zero, we get a deterministic linear trend. If $\sigma_{\xi}^{2}$ is zero and $\sigma_{\varepsilon}^{2}$ is strictly positive, the model collapses to a random walk with a constant drift rate. The opposite case with a strictly positive $\sigma_{\xi}^{2}$ and $\sigma_{\varepsilon}^{2}$ equal to zero gives an integrated random walk with an usually smooth trend component. 
The cycle $C_{t}$ captures the fluctuations around the trend component and is modelled as the sum of $M$ subcycles:

(4) $\quad C_{t}=\sum_{i=1}^{M} C_{t, i}$.

Each subcycle is specified as a vector AR (1) process:

$$
\left(\begin{array}{c}
C_{t, i} \\
C_{t, i}^{*}
\end{array}\right)=\rho_{i}\left(\begin{array}{cc}
\cos \lambda_{i}^{C} & \sin \lambda_{i}^{C} \\
-\sin \lambda_{i}^{C} & \cos \lambda_{i}^{C}
\end{array}\right)\left(\begin{array}{l}
C_{t-1, i} \\
C_{t-1, i}^{*}
\end{array}\right)+\left(\begin{array}{c}
\kappa_{t, i} \\
\kappa_{t, i}^{*}
\end{array}\right) .
$$

$C^{*}$ appears only by construction and has no intrinsic interpretation.

The period of subcycle $\mathrm{i}$ is $2 \pi / \lambda_{i}^{C}$. The damping factor $\rho_{i}$ with $0<\rho_{i} \leq 1$ ensures that $C_{t, i}$ is a stationary $\operatorname{ARMA}(2,1)$ process with complex roots in the $A R$-part (see Harvey, 1989). This guarantees a quasi-cyclical behaviour of $C_{t, i}$. The shocks $\kappa_{t, i}$ and $\kappa_{t, i}^{*}$ are assumed to be uncorrelated white noise variables with common variance $\sigma_{\kappa_{i}}^{2}$. They induce a stochastically varying phase and amplitude of the wave-like process. The total cycle $C_{t}$ is an $\operatorname{ARMA}(2 M, 2 M-1)$ process with restricted $M A$-parameters.

The seasonal component captures the typical intra-year fluctuations of production. For example, in most years we observe a trough in production in August and a peak in November. The seasonal fluctuations in production are caused by seasonal fluctuations in demand, by weather effects on productivity and by the division of vacation times over the different months. As will be explained below, parts of these effects are modelled as functions of observable variables.

The seasonal effect is specified as the sum of six cycles with the seasonal frequencies $\lambda_{i}=2 \pi i / 12, \mathrm{i}=1,2, \ldots, 6$ :

(6) $S_{t}=\sum_{i} S_{t, i}$.

Following Harvey (1989), we specify each seasonal cycle by a stochastic recursive formula:

(7) $\left(\begin{array}{l}S_{t, i} \\ S_{t, i}^{*}\end{array}\right)=\left(\begin{array}{cc}\cos \lambda_{i} & \sin \lambda_{i} \\ -\sin \lambda_{i} & \cos \lambda_{i}\end{array}\right)\left(\begin{array}{l}S_{t-1, i} \\ S_{t-1, i}^{*}\end{array}\right)+\left(\begin{array}{c}\omega_{t, i} \\ \omega_{t, i}^{*}\end{array}\right)$. 
In an analogous way to the specification of the cycle component, the auxiliary variable $S^{*}$ is only used for building up the recursion.

The seasonal shocks $\left(\omega_{t, i}, \omega_{t, i}^{*}\right)$ are two uncorrelated white noise random variables with common variance $\sigma_{\omega_{i}}^{2}$. If the variance of a seasonal shock is greater than zero, the seasonal pattern changes over time. In most applications, the variances of the seasonal shocks are restricted to be constant over the different seasonal frequencies. In order to get a more flexibel model, we allow for different variances for different frequencies (this feature is called trigonometric seasonal heteroscedasticity by Koopman/Franses, 2001).

The calendar effect $A_{t}$ comprises the working day effect $D_{t}$, the bridging day effect $B_{t}$ and the main vacation effect $V_{t}$. The working day effect $D_{t}$ is caused by the varying number of the different days of the week and the occurence of public holidays. In exploratory work we tried different specification for the working day effect (see for example, the suggestions in Harvey, 1989, and Ladiray/Quenneville, 2001). The best model (evaluated by the diagnostic measures presented below) is given by

$$
D_{t}=\sum_{j} \beta_{t, j}^{(1)}\left(T D_{t, j}-\overline{T D_{j}}\right),
$$

where $T D_{t, j}$ denotes the number of days of type $j$ in period $t$ and $\overline{T D_{j}}$ is the average number of days of type $j$ over the estimation period. The weighting parameters $\beta$ are allowed to change over time (see below). This formulation ensures that the working day effect has approximately a zero average over the estimation period. The precise definition of the different types of days is given below in the empirical section.

If a public holiday falls on a Tuesday or a Thursday, many workers choose to take a vacation day at Monday or Friday, respectively. Those days are called "Brückentage" (bridging days). In months with more bridging days, production is expected to be lower. The bridging day effect is specified as

$$
B_{t}=\beta_{t}^{(2)}\left(T B_{t}-\overline{T B}\right),
$$

when $T B_{t}$ is the number of bridging days in month $t$, and $\overline{T B}$ is the average number of bridging days over the estimation period.

In Germany, the main vacation period starts mid June and ends early September. Unfortunately, we have no statistic on the distribution of the vacation of produc 
tion workers over these months. Instead, we use the pattern of school holidays as an indicator variable. The vacation effect is specified as

$$
V_{t}=\beta_{t}^{(3)}\left(V S_{t}-0.25\right),
$$

where $V S_{t}$ is the proportion of summer school holidays in a given year which falls in period $t$ (for a detailed description of VS see the appendix). Note that $V S_{t}$ is zero for all months with the exception of June, July, August and September. $\left(V S_{t}-0.25\right)$ measures the deviation of the actual distribution from a hypothetical uniform distribution of the vacation period over the four vacation months. The specification (10) ensures that the vacation effect is approximately zero over a year.

We expect that the parameters $\beta$ in equations (8) to (10) are not constant over time. For instance, the number of working hours per week shows a sharp decrease from about 45 hours in the late fifties to about 37 hours at the end of the nineties, the number of vacation days increased from 15 to more than 30 and the phenomenon of flexitime is now much more common than it used to be in the past. For all these reasons, we suspect that the importance of the number of working and bridging days as well as the vacation period is changing over time.

In order to allow for possibly time-varying effects, we specify the parameters $\beta_{t}^{(i)}, i=1,2,3$ as random walks

$$
\beta_{t}^{(i)}=\beta_{t-1}^{(i)}+\eta_{t, i},
$$

where $\eta_{t, i}$ is a white noise random shock with variance $\sigma_{\eta_{i}}^{2}$.

The irregular component comprises a deterministic and a stochastic component:

$$
I_{t}=\gamma_{0} D I_{t}+u_{t}
$$

$D I_{t}$ is a dummy variable which takes the value 1 in a certain period and the value 0 in all other periods. The deterministic component $\gamma_{0} D I_{t}$ (the impulse intervention) captures outliers which reflect identifiable events and $u_{t}$ reflects temporary shocks which are modelled as a stochastic variable. In most applications, $u_{t}$ is assumed to be a white noise variable with a constant variance $\sigma_{u}^{2}$.

A careful look at the estimated irregular component and the one-step prediction error shows that this assumption is greatly at odds with the empirical facts: The 
standard errors are in some months (especially in July, August and December) much higher than in other months (e.g., in October or November). For this reason we allow the variance of the random component of the irregular to follow a deterministic seasonal pattern:

$$
\operatorname{Var}\left(u_{t}\right)=\sigma_{u}^{2}(\tau), \tau=1, \ldots, 12,
$$

where $\tau$ denotes the month (January, . . December) in which period $t$ falls. This feature of month-specific variances of the irregular component is called seasonal heteroscedasticity by Koopmann/Franses (2001). For alternative specifications of seasonal heteroscedasticity see Jaditz (2000), Campbell/Diebold (2001) or Burridge/Wallis (1990).

It is assumed that all disturbances are normally distributed and are independent of each other. This is the usual assumption to assure the identification of the parameters (see, e.g., Watson 1986).

Estimation of the model parameters is carried out by maximum likelihood in the time domain. The initial values for the stationary cycle components are given by the unconditional distribution and for the nonstationary trend, drift and seasonal components by a diffuse prior. The time-varying parameters $\beta$ in equations (8) to (10) are also initialised by using a diffuse prior. The filtered and smoothed values of the unobserved components are generated by the Kalman filter (for details see Harvey 1989).

\section{Empirical results}

The variable analysed in this study is a monthly index of German industrial production, defined as the output of manufacturing, mining and energy producing utilities (for details see Appendix). The estimation period includes 564 months, extending from January 1955 to December 2001.

In a first step, we seek for a parsimonious specification of the working day effect and for possible outliers which should be controlled for by a deterministic intervention variable. In all versions it turns out that the estimated values for the smoothed irregular component were exceptionally high in December 1967 (positive) and July 1984 (negative). The December 1967 outlier may be due to a fundamental change in the tax system in January 1968 (introduction of the value added tax) which led to a temporarily increase in production in the previous month. The outlier in July 1984 can be easily explained by a strike in the metal industry. 
Concerning the working day effect, an intensive search over several specifications was carried out. In the basic model, the number of Mondays, Tuesdays, ..., Saturdays, that are not public holidays, the number of Sundays and the number of public holidays were included as explanatory variables. It turns out that the estimated time-varying parameters for the number of Mondays to Fridays (that are not holidays) are not significantly different from each other and that the parameters for the number of Sundays and the number of holidays are likewise almost identical. Consequently, in the final model, we use the sum of the number of Mondays to Fridays (that are not holidays), the number of Saturdays (that are not holidays) and the sum of the number of Sundays and holidays as the three variables for modelling the working day effect. This specification is more flexibel than the approach used by the German statistical office and the Bundesbank where Saturdays have the same effect as Sundays and holidays (see Kirchner, 1999). The "Bundesbank-restriction" was clearly rejected in all models we present below.

Given the specification for deterministically modelled outliers and for the working day effect, we estimate eight different models which differ with respect to the form of seasonal heteroscedasticity, the inclusion of bridging days and the vacation indicator.

Model I, called the extended basic structural time series model, consists of a stochastic trend, cycle and seasonal component, but includes none of the working day, bridging day and vacation effects and assumes a constant variance for the seasonal shocks of different frequencies as well as a constant variance of the irregular over the months of a year.

Model II adds the working day effect, model III in addition the bridging day effect and model IV the main vacation effect. Model $V$ allows for trigonometric seasonal heteroscedasticity and model VI in addition for seasonal heteroscedasticity of the irregular component. As explained in detail below, model Vla imposes some restrictions on the monthly variances of the irregular. Model VII is equal to model Vla with the exception that the cyclical component is specified as the sum of two subcycles (for some evidence concerning German GDP, see Flaig, 2002). Table I gives a short summary of the estimated models.

\section{Table I: Summary of Estimated Models}

\begin{tabular}{|l|l|}
\hline Model I & Extended basic structural time series model \\
\hline Model II & Model I + working day effect \\
\hline Model III & Model II + bridging day effect \\
\hline
\end{tabular}




\begin{tabular}{|l|l|}
\hline Model IV & Model III + main vacation effect \\
\hline Model V & Model IV with trigonometric seasonal heteroscedasticity \\
\hline Model VI & Model V with seasonal heteroscedasticity for irregular \\
\hline Model VI a & Model VI with restrictions for variances of irregular (see text) \\
\hline Model VII & Model VI a with two cycles \\
\hline
\end{tabular}

We compare the quality of the different models by using several fit criteria and diagnostic measures. Since we initialise the non-stationary elements of the state vector by a diffuse prior, the likelihood function is effectively calculated by using the one-step-ahead prediction errors for the periods $d+1, \ldots, T$, where $d$ denotes the number of non-stationary states and $T$ is the number of observations (to be concrete, we maximise the likelihood function as given by equation (4.2.3) in Harvey, 1989; for an exact solution see Durbin/Koopman, 2001). In order to be able to compare the fit criteria for models with a different number of non-stationary state variables, we normalise the likelihood function $\ln L$ by multiplying it by the factor $T /(T-d)$. The expression $\ln L^{*}=\ln L \cdot(T / T-d)$ specifies the value of the likelihood function per effective observation multiplied by the total number of observations. Due to well-known problems with the application of likelihood-ratio tests for structural time series models (see Harvey, 1989), we use $\ln L^{*}$ only in an informal way and rely on the Akaike and Schwarz information criteria. Further, we check the standardised prediction errors for the presence of autocorrelation and non-normality by using the Box-Ljung and Jarque-Bera test, respectively.

The results are presented in Table 2. As it turned out that the variance of the level shock $\varepsilon_{t}$ (equation (2)) has in all models an estimated value of zero or almost zero, we impose this restriction for all versions presented in the following. All criteria show very clearly that the inclusion of the working day and the bridging day effect as well as the main vacation indicator improves considerably the quality of the model (compare models II to IV with the basic model I). Whereas the working day effected is taken into account by procedures used in official statistical agencies, the latter two effects are mostly neglected. Model $V$ reveals that the assumption of a common variance for the seasonal shocks of different frequencies (equation (7)) is to restrictive and should be relaxed. In model VI, we allow for month-specific variances of the irregular component. The evidence is somewhat mixed. Whereas the Akaike information criterion indicates an improvement, the Schwarz information criterion shows a deterioration. The latter is due to the fact 
that the Schwarz criterion penalises the additional eleven parameters very heavily. A closer look at the estimated variances reveals that the estimated variances are very similar in January and March, in July and in December, and in the group of the other months, respectively.

If we impose the according restrictions, both the Akaike and the Schwarz information criterion select model Vla with seasonal heteroscedasticity of the irregular shock as the best. Finally, in model VII we specify the cyclical component as the sum of two subcycles. Despite the fact that the Schwarz criterion deteriorates, we choose version VII as our preferred model. Model VII delivers the best result concerning the Akaike criterion (for some arguments why AIC is a reliable measure for model selection see Kitagawa/Gersch, 1996) and shows no sign of misspecification. 
Table 2: Summary Statistics

\begin{tabular}{|c|c|c|c|r|r|c|}
\hline Model & $\ln L^{*}$ & \multicolumn{1}{|c|}{ AIC } & \multicolumn{1}{|c|}{ SIC } & \multicolumn{1}{c|}{ LB } & JB & $\sigma_{R R}$ \\
\hline I & $1,037.3$ & $-2,032.6$ & $-1,942.0$ & 278.6 & 0.6 & 0.0385 \\
\hline II & $1,494.9$ & $-2,933.7$ & $-2,813.1$ & 13.7 & 5.9 & 0.0172 \\
\hline III & $1,503.0$ & $-2,948.0$ & $-2,823.2$ & 11.8 & 9.4 & 0.0170 \\
\hline IV & $1,556.7$ & $-3,051.3$ & $-2,917.9$ & 18.3 & 4.3 & 0.0167 \\
\hline V & $1,576.9$ & $-3,081.9$ & $-2,927.0$ & 5.4 & 4.5 & 0.0163 \\
\hline VI & $1,592.1$ & $-3,090.2$ & $-2,887.9$ & 5.9 & 1.2 & 0.0162 \\
\hline VI a & $1,589.7$ & $-3,102.9$ & $-2,939.4$ & 5.8 & 1.2 & 0.0161 \\
\hline VII & $1,595.6$ & $-3,109.2$ & $-2,932.8$ & 4.3 & 1.2 & 0.0159 \\
\hline
\end{tabular}

Note: $\ln L^{*}$ is the normalised value of the maximised likelihood function, AIC the Akaike information criterion, SIC the Schwarz information criterion, LB the Ljung-Box-statistic with 12 lags, JB is the Jarque-Bera test-statistic, and $\sigma_{R R}$ is the standard deviation of the one-step prediction errors.

Table 3 presents the estimated parameters for model VII. Almost all of the estimated standard deviations of the various shocks are highly significant and imply that the unobserved components (trend, cycles, etc.) are stochastically varying over time. The effects of the individual parameters are explained in detail below. 
Table 3: Parameter Estimates for Model VII

\begin{tabular}{|c|c|c|c|c|}
\hline Trend & $\sigma_{\xi}: 1.64$ & ( 2.9) & & \\
\hline \multirow{2}{*}{ Season } & $\sigma_{\omega_{1}}: 10.53$ & ( 6.3) & $\sigma_{\omega_{2}}: 4.92 \quad(3.8)$ & $\sigma_{\omega_{3}}: 4.43 \quad(4.2)$ \\
\hline & $\sigma_{\omega_{4}}: \quad 0.0$ & $(0.0)$ & $\sigma_{\omega_{5}}: 1.99 \quad(2.8)$ & $\sigma_{\omega_{6}}: 1.01 \quad(1.4)$ \\
\hline \multirow{2}{*}{ Cycle } & $\rho_{1}: \quad 0.977$ & $(206.4)$ & $\lambda_{1}^{C}: 0.118$ & $\sigma_{\kappa_{1}}: 57.44 \quad(13.2)$ \\
\hline & $\rho_{2}: \quad 0.993$ & $(885.1)$ & $\lambda_{2}^{C}: 0.054 \quad(8.6)$ & $\sigma_{\mathrm{K}_{2}}: 36.80 \quad(9.3)$ \\
\hline $\begin{array}{l}\text { Working } \\
\text { Day Effect }\end{array}$ & $\sigma_{\eta_{1}}^{(1)}: 2.99$ & $(2.8)$ & $\sigma_{\eta_{2}}^{(1)}: 2.70 \quad(1.9)$ & $\sigma_{\eta_{3}}^{(1)}: \quad 0.0 \quad(0.0)$ \\
\hline $\begin{array}{l}\text { Bridging } \\
\text { Day Effect }\end{array}$ & $\sigma_{\eta}^{(2)}: 4.33$ & $(2.3)$ & & \\
\hline $\begin{array}{l}\text { Vacation } \\
\text { Effect }\end{array}$ & $\sigma_{\eta}^{(3)}: 50.82$ & $(10.3)$ & & \\
\hline \multirow{2}{*}{ Irregular } & $\gamma_{67: 12}: 0.066$ & $(5.9)$ & $\gamma_{84: 6}:-0.132 \quad(12.3)$ & \\
\hline & $\sigma_{u}^{(1)}: 70.84$ & & $\sigma_{u}^{(2)}: 109.68$ (13.0) & $\sigma_{u}^{(3)}: 41.84 \quad(23.1)$ \\
\hline
\end{tabular}

Note: All standard deviations of shocks have to be multiplied by $10^{-4}$. Numbers in parentheses denote $t$-values.

The three values for the standard deviations of the working day effect refer to the parameter of the number of Mondays to Fridays, Saturdays, and Sundays and holidays, respectively. The three values for the standard deviations of the irregular component refer to January and March, July and December, and to the other months, respectively.

In the following, we discuss the evolution of the unobserved components as well as the time-varying model parameters for the working day, the bridging day and the vacation effects. The figures display the smoothed values which were generated by the fixed-interval smoother.

Figure 1 shows the logarithm of the production index (thin line) and the estimated trend component (thick line). The graph demonstrates how flexible a specification with a time-varying drift rate can accommodate the slowdown of the growth rate in the early sixties and early seventies as well as the hump in the second half of the eighties. 
Figure 1: Production Index (thin line) and Trend Component (thick line)

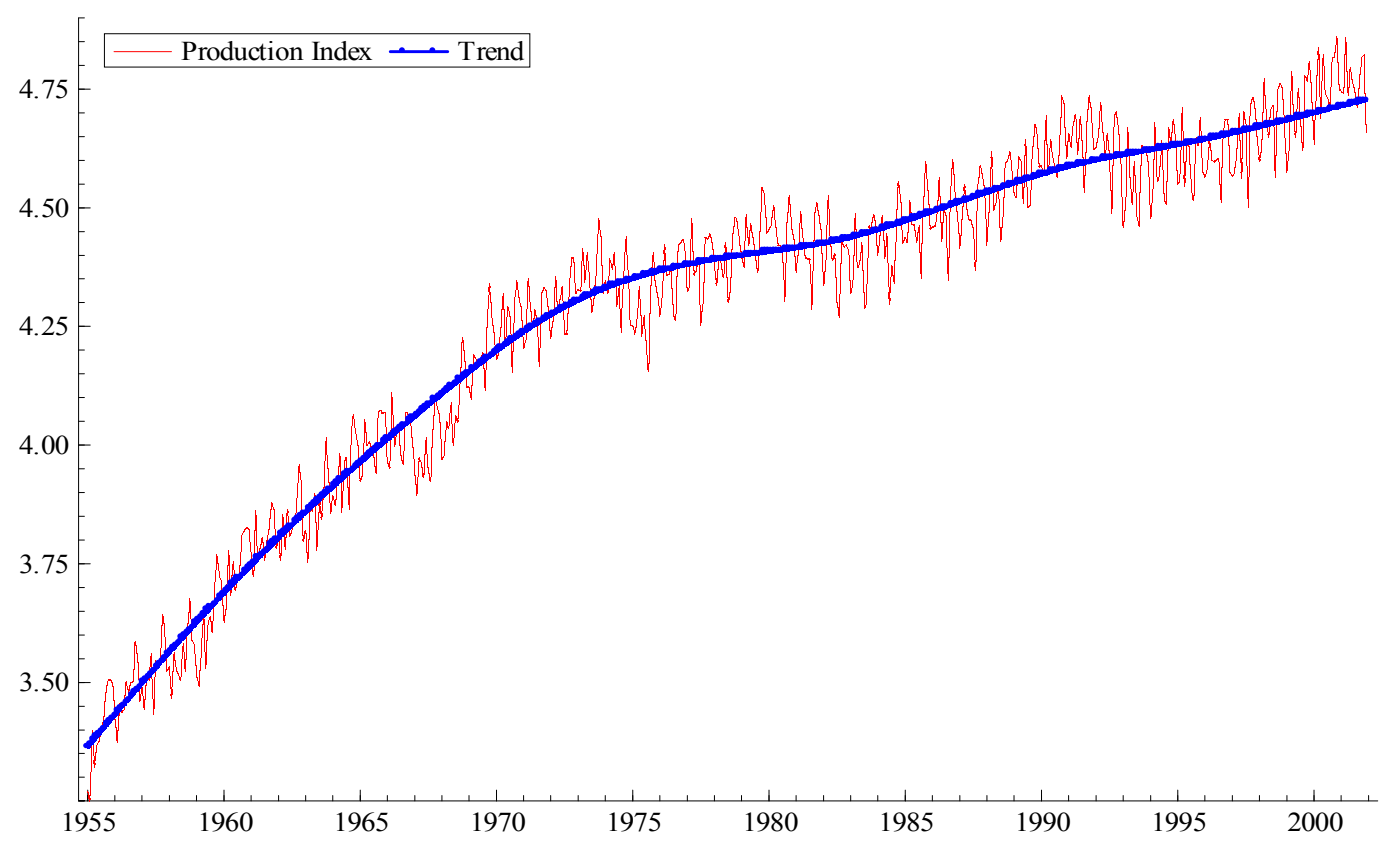

Figure 2 displays the short- and the long cycle as well as the total cycle. The short cycle has a period of 53 months (4.4 years) and a standard deviation of 0.023 , the long cycle has a period of 116 months (9.7 years) and a standard deviation of 0.026 . The total cycle has a standard deviation of 0.038 .

It is interesting that in previous work (Flaig 2002) we found a similar cyclical pattern for quarterly German GDP in the period from 1960 to 2001. The estimated periods for the two subcycles of GDP are 4.1 and 8.1 years. Whereas the periodicity of the short cycle is almost identical for GDP and the production index, the periodicity of the long cycle of GDP is 1.6 years higher than in case of the production index. But since the standard error for the periodicity of the long cycle is 1.2 years, we can conjecture that GDP and industrial production follow similar cycles. A formal investigation of this conjecture is left for future research. 
Figure 2: Short Cycle, Long Cycle and Total Cycle
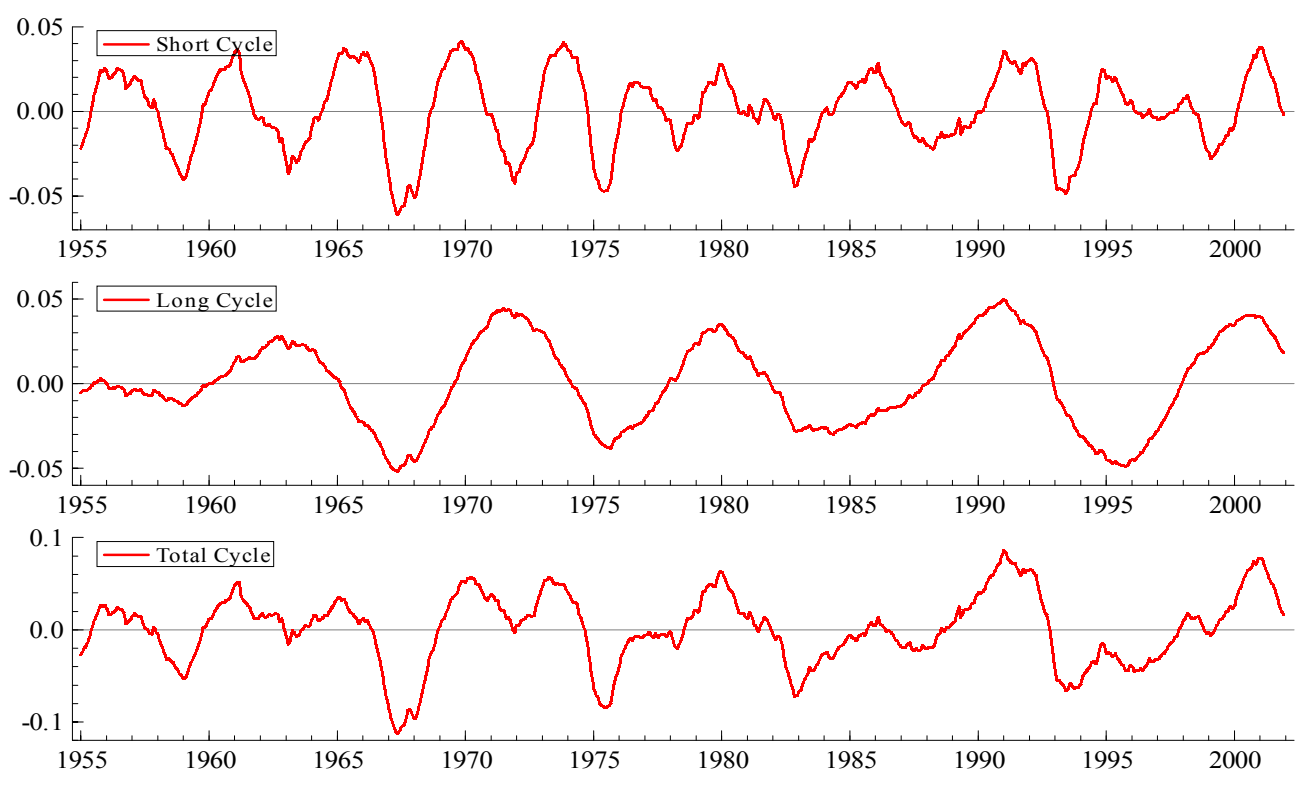

Figure 3 displays the smoothed estimate of the seasonal component. As can easily be seen, the seasonal pattern is changing over time. Especially the yearly minima (in January, July and August) are much more pronounced in the second half of the sample than in the fifties and sixties. In the last 15 years, we observe a slight reduction in the seasonal fluctuations. The variable seasonal pattern casts some doubts on the claim of some authors (see, e.g., Miron, 1996) that the seasonal cycle could reasonably be modelled by using fixed seasonal dummies.

Imposing the restriction that the variances of the seasonal shocks are zero (which is equivalent to assuming a fixed seasonal pattern) leads to high autocorrelation of the recursive residuals and is rejected by all diagnostics. A stochastic seasonal process is essential for an adequate specification. It is a very misleading assertion that "these processes allow for Christmas to migrate to July" (Miron, 1996, p.8). But they allow, e.g., that the strength of Christmas effect is changing over time. And that is what we would expect to occur over longer time horizons. 
Figure 3: Season

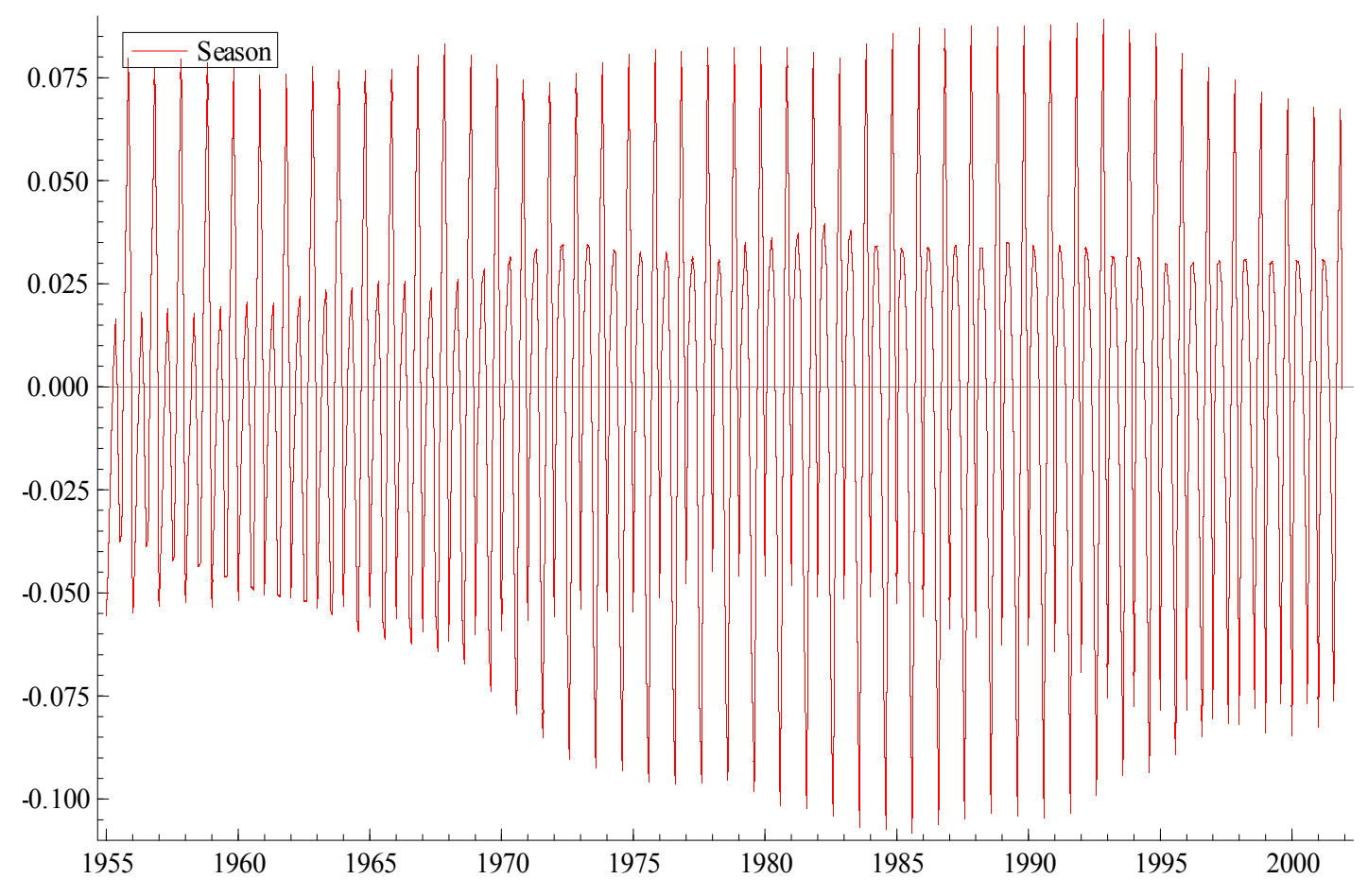

Figure 4 and Figure 5 display the estimated parameters for the calendar effects. The topmost curve in Figure 4 shows the time-varying parameter for the number of Mondays to Fridays. The parameter starts in 1955 with a value of 0.034 , increases to 0.037 in 1961, falls then to a minimum of 0.032 in the seventies and shows since then an increase to about 0.038 . The next curve from the top refers to the Saturday effect. The parameter decreases steadily from 0.019 to 0.012 in the eighties and increases since then slightly to a value of about 0.014 . The sharp decrease is due to the fact that Saturday was abolished as a regular working day during the fifties and sixties, the increase during the last two decades reflects the attempt of firms to use their plant also on Saturdays.

The thick horizontal line with a value of 0.058 represents the Sunday and holiday effect on production. Since the variance of the shock for this parameter is zero, the smoothed parameter is constant over the last fifty years. The curve in the bottom part of Figure 3 shows the parameter for the bridging day effect. It is relatively small until the middle of the seventies but then triples (in absolute terms) in the last two decades. The higher importance of bridging days since the seventies is mainly caused by the already mentioned high increase in the total number of vacation days which are used to take a day off before or after a public holiday. 
Figure 4: Estimates for the Parameters of the Working Day and Bridging Day Effects

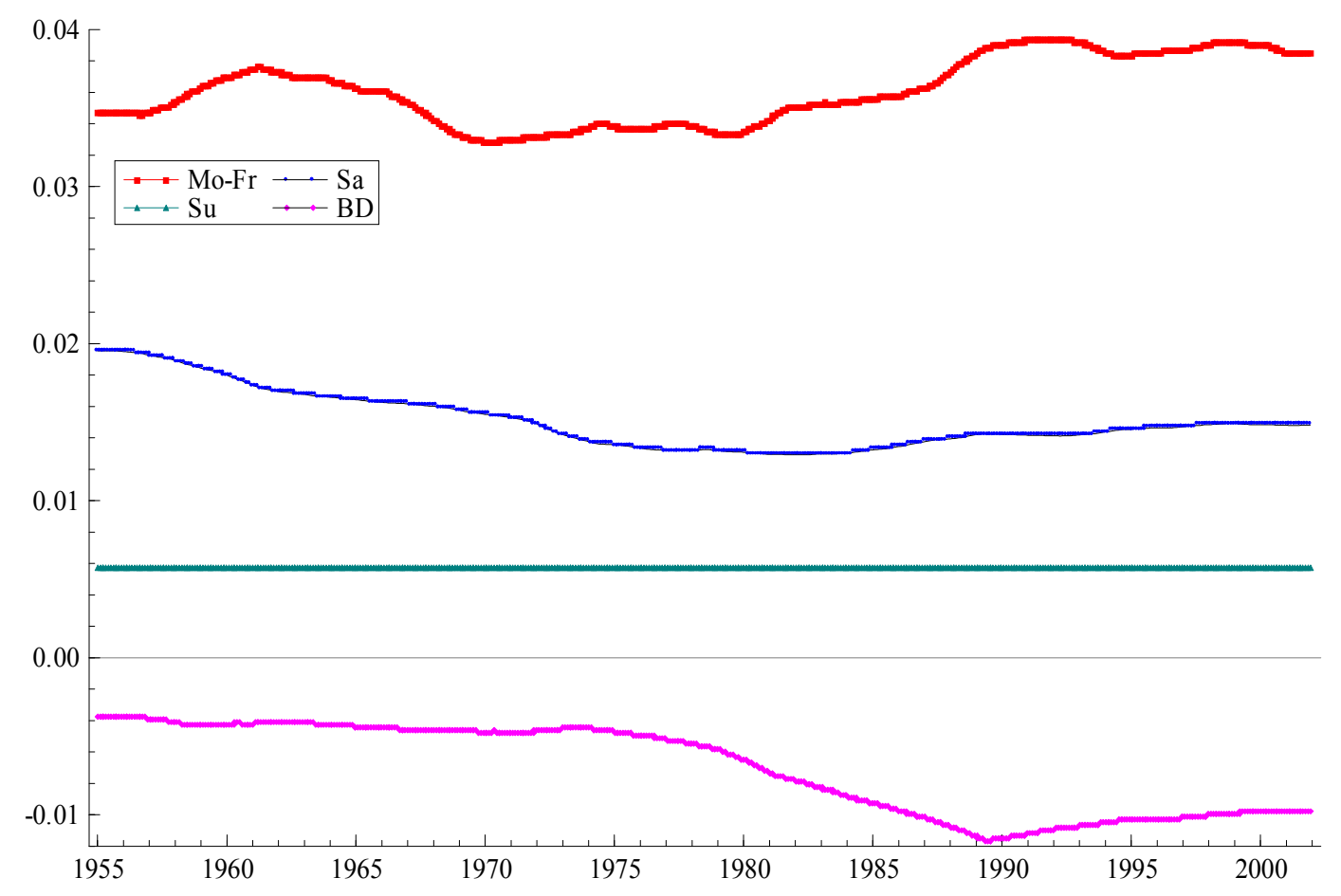

Figure 5 presents the smoothed values for the parameter of the summer vacation effect. In a qualitative sense, the parameter exhibits similar properties as the parameter for the bridging day effect. The parameter shows a pronounced trend until the mid seventies and fluctuates since then around the value -0.25 . 
Figure 5: Estimates for the parameter of the Vacation Effect

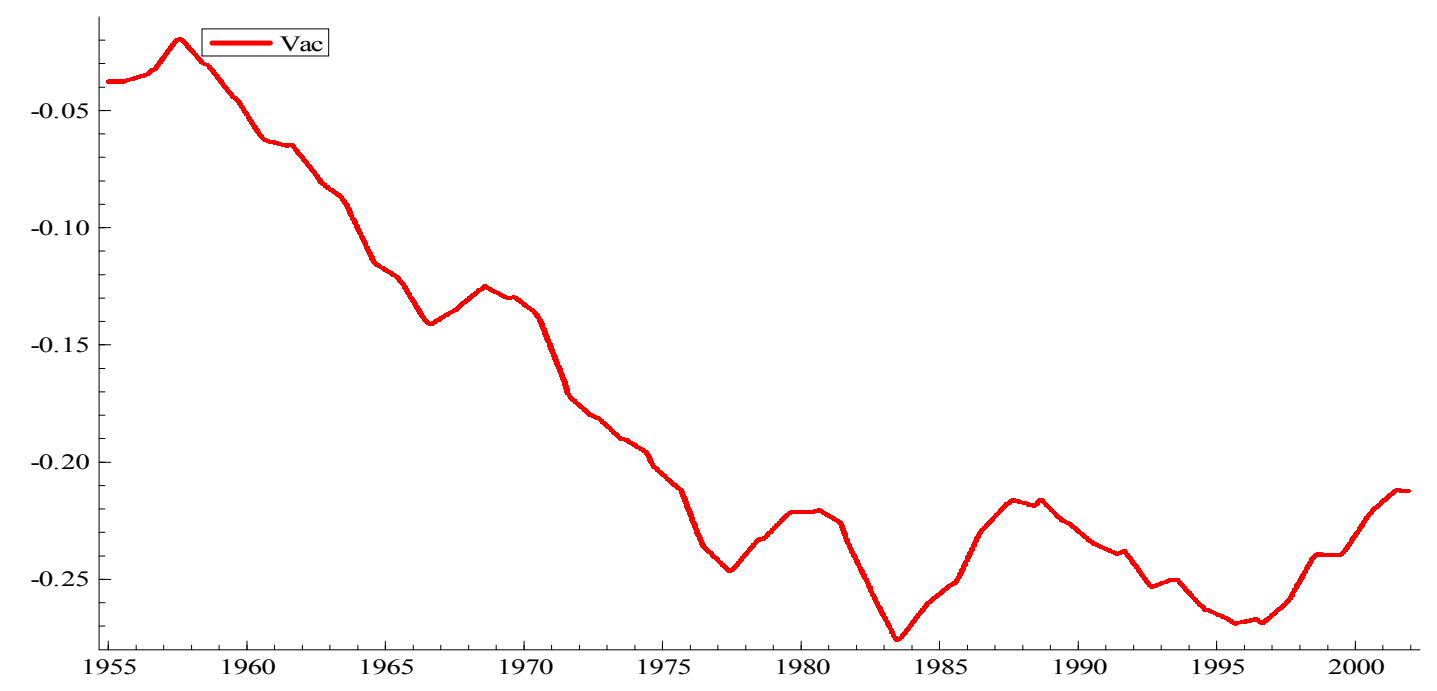

The total calendar effect comprises the working day, the bridging day and the summer vacation effect. It's contribution to the short-run dynamics of production is shown in the top part of Figure 6 . As the decomposition of the intra-year fluctuations into the seasonal and calendar component is somewhat arbitrary, the sum of both components is displayed in the bottom part of Figure 6 . When we compare Figure 6 with Figure 2, we see that the intra-year fluctuations are almost one and a half as large as the fluctuation at business cycle frequencies. There is an enormous short-run volatility of production which have to be modelled very carefully in order to purge the time series from noisy elements. 
Figure 6: Total Calendar Effect
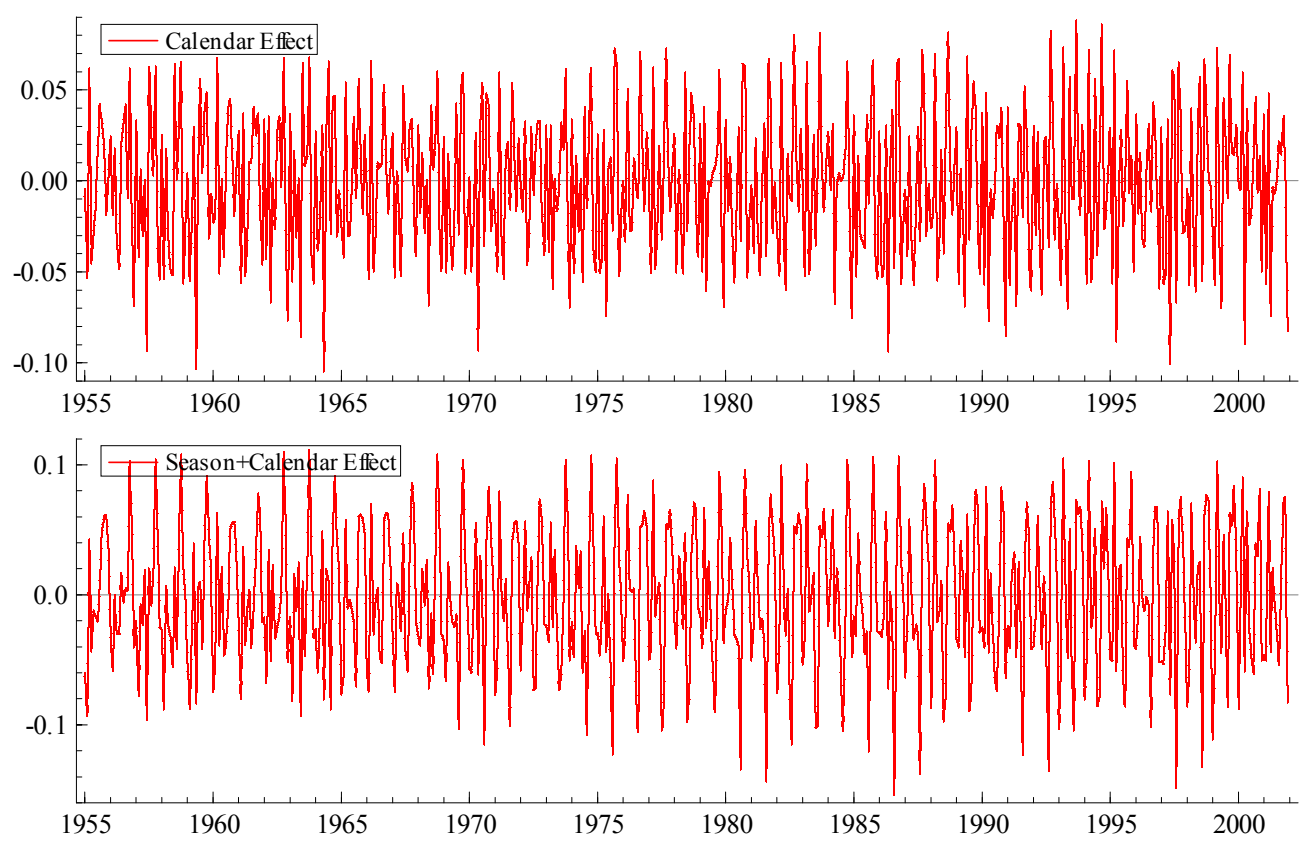

The smoothed values for the irregular component are presented in Figure 7. As could be expected from the estimated values for the month-specific variances of the irregular (see Table 3), the highest values occur in January and March and especially in August and December.

\section{Figure 7: Irregular Component}

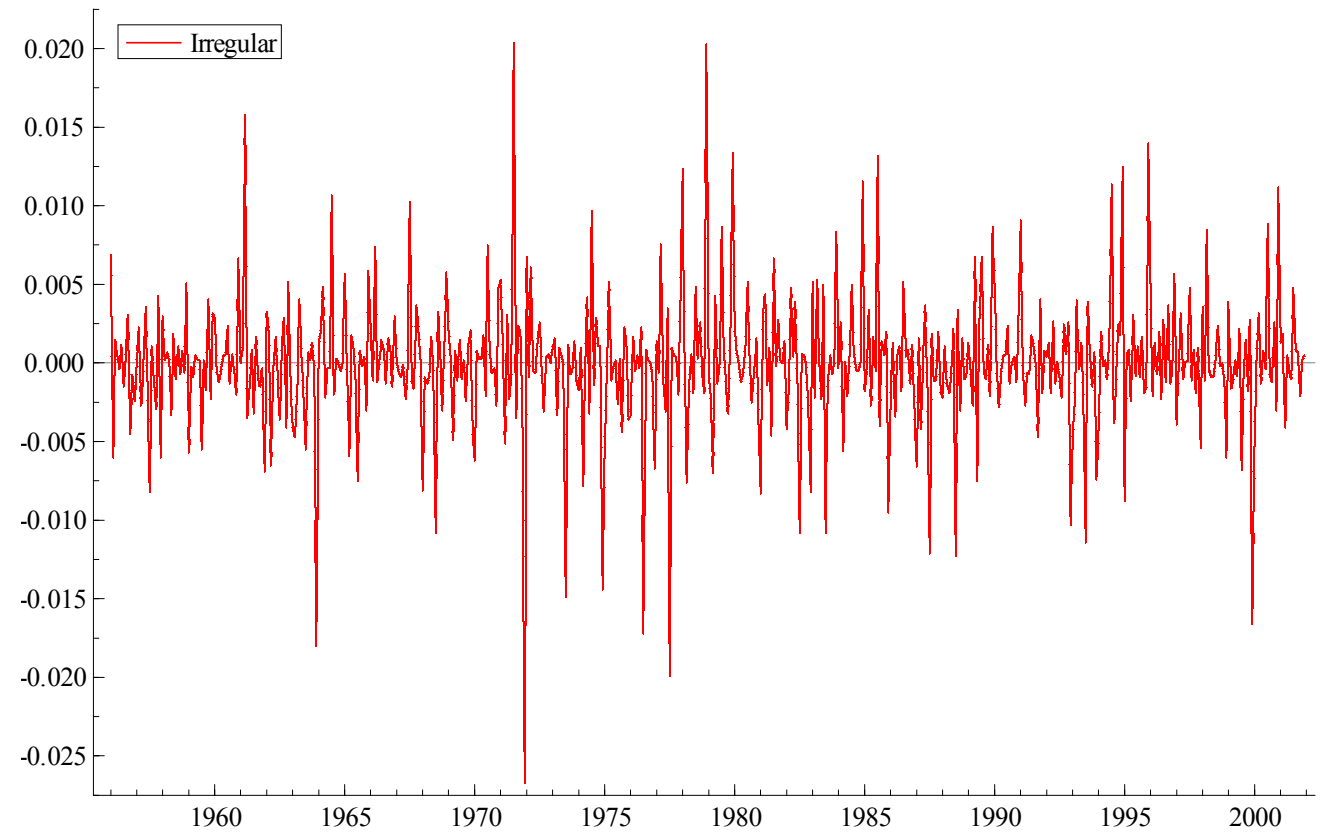




\section{Summary and Conclusions}

In this study, we use an Unobserved Components Model for decomposing the monthly German production index into trend, cycle, season, the calendar effects and the irregular. The most important results can be summarised as follows:

1. The trend component can successfully be modelled as an integrated random walk, i.e., as an I(2)-process. This specification is able to reproduce the slowdown in the long-run growth rate during the early sixties and early seventies. A specification of the trend component as an I(1)-variable with a constant drift rate would not be able to capture this pattern.

2. The cycle consists of two subcycles with a period of 4.4 and 9.7 years, respectively. This is in full accordance with empirical results for German GDP (see Flaig 2002) and central ideas in classical business cycle theory about Kitchin- and Juglar-cycles.

3. The seasonal pattern of production is changing over time. A stochastic specification of the seasonal component is a crucial feature of a satisfactory time series model for the production index. In addition, we observe trigonometric heteroscedasticity. The variances of the seasonal shocks are different for the different seasonal frequencies. The restriction of a constant variance as for instance imposed in STAMP (Koopman / Harvey / Doornik / Shephard, 2000) seems not to be the best choice at least for the time series analysed in this paper.

4. For a successful modelling of the working day effect it seems to be necessary to distinguish between four types of days: Weekdays, Saturdays, Sundays and public holidays, and bridging days. As yet, the bridging day effect is not taken into account by any official seasonal adjustment procedure. The same is true for the summer vacation effect which is caused by the time-varying start and end of school holidays. In addition, the parameters for these variables are changing over time. A constant parameter as imposed in all seasonal adjustment procedures is to restrictive, especially if we analyse long time series. The results of this paper delivers strong evidence that the "official" seasonal adjustment procedures can considerably be improved by taking into account the bridging day and vacation effect. This observation may be relevant also in other countries in which these phenomena are important.

5. The variability of the irregular component is not constant over the months of a year. The variance is especially high in January, March, July and December. January, July and December may sometimes be affected by very cold or hot 
weather conditions but the main cause is probably a vacation effect around Christmas and Easter as well as a peculiar effect in July which is not fully captured by the school holiday indicator developed in this paper.

As yet we have not found a satisfactory specification of the Easter and Christmas effect as a function of observable variables (for a discussion of different approaches see Ladiray/Quenneville, 2001). It is left for future work to carry out a systematic specification search in order to reduce the variance of the irregular component.

6. Unobserved Components Models are a very useful and efficient approach for modelling economic time series with complex properties like stochastic trend and seasonal components, time-varying parameters of explanatory variables and period-specific variances of shocks. They are far more flexible than ARIMA-models commonly used in empirical work. 


\section{Appendix: Data}

The production index comprises total industry, excluding construction. The data for 1955 to 1990 refer to West Germany and are taken from the CD-ROM "50 Jahre Deutsche Mark", published by Deutsche Bundesbank. The data for 1991 to 2001 cover Germany and are taken from the CD-ROM "STATIS", published by Statistisches Bundesamt. The index values from 1955 to 1990 are multiplied by the factor 1,054 in order to take account for a change in the base year.

The number of working days, bridging days, and public holidays are calculated by a GAUSS program, written by the author (available on request). We count for every months in the sample how often each day of the week occurs and how many public holidays fall on each day of the week. We take into account that some of the public holidays are valid only in part of the German Länder. Public holidays are: January $1^{\text {st }}$, January $6^{\text {th }}$ (Epiphany, 0.3 ), Good Friday, Easter Monday, May $1^{\text {st }}$, Ascension, Corpus Christi Day (0.7), Whit-Monday, June $17^{\text {th }}$ (until 1990), August $15^{\text {th }}$ (Assumption Day, 0.2), October $3^{\text {rd }}$ (German Unification Day, since 1990), Reformation Day (0.1, since 1991), All Saints' Day (0.6), Christmas Eve (0.5), New Years' Eve (0.5).

When a public holiday falls on a Tuesday or on a Thursday, many people take a vacation at the preceding Monday or the following Friday, respectively. These days are called bridging days (Brückentage). Each bridging day is counted with the weight of the corresponding public holiday.

In contrast to other countries, in Germany the summer vacation period of workers is not fixed but is mainly determined by school holidays which change from year to year in each federal state. The secretariat of the Deutsche Kultusministerkonferenz provided kindly the dates of the school holidays in every federal state since 1955. From this information we calculated for each state the proportion of school holiday which fall in June, July, August and September, respectively. The figure for the whole country was calculated as a weighted average where the weight of a state is given by its share of the number of production workers. 


\section{References}

Burridge, P. / K.F. Wallis (1990), Seasonal Adjustment and Kalman Filtering: Extension to Periodic Variances. Journal of Forecasting, 9, 109-118.

Campbell, S. / F.X. Diebold (2001), Weather Forecasting for Weather Derivatives. Penn Institute for Economic Research Working paper 01-031.

Durbin, J. / Koopman, S. J. (2001), Time Series Analysis by State Space Methods. Oxford: Oxford University Press.

Flaig, G. (2002), Unobserved Components Models for Quarterly German GDP. CESifo Working Paper No. 681.

Harvey, A. (1989), Forecasting, Structural Times Series Models and the Kalman Filter. Cambridge: Cambridge University Press.

Harvey, A. / A. Jaeger (1993), Detrending, Stylized Facts, and the Business Cycle. Journal of Applied Econometrics 8, 231-47.

Jaditz, T. (2000), Seasonality in Variance is Common in Macro Time Series. Journal of Business, 73, 245-254.

Jung, S. (2002), Erfahrungen mit dem Saisonbereinigungsverfahren Census X12-ARIMA für den Produktionsindex. Wirtschaft und Statistik, 797-801.

Kirchner, R. (1999), Auswirkungen des neuen Saisonbereinigungsverfahrens X12-ARIMA auf die aktuelle Wirtschaftsanalyse in Deutschland. Diskussionspapier 7/99. Deutsche Bundesbank.

Kitagawa, G. / Gersch, W. (1996), Smoothness Priors Analysis of Time Series. New York, Berlin, Heidelberg: Springer.

Koopman, S. J. / Harvey, A. / Doornik, J. / N. Shephard (2000), STAMP. Structural Time Series Analyser, Modeller and Predictor. London: Timberlake Consultants.

Koopman, S. J. / P.H. Franses (2001), Constructing Seasonally Adjusted Data with Time-varying Confidence Intervals. Econometric Institute Report El 200102, Erasmus University Rotterdam.

Ladiray, D. / Quenneville, B. (2001), Seasonal Adjustment with the X-11-Method. New York, Berlin, Heidelberg: Springer-Verlag.

Maravall, A. (1995), Unobserved Components in Economic Time Series. In: Pesaran, H. and T.R. Wickens (eds.), Handbook of Applied Econometrics - Macroeconomics, Oxford: Blackwell, 12-77.

Miron, J.A. (1996), The Economics of Seasonal Cycles. Cambridge/London: MIT Press.

Watson, M. (1986), Univariate Detrending Methods with Stochastic Trends. Journal of Monetary Economics 18, 49-75. 


\section{CESifo Working Paper Series}

(for full list see www.cesifo.de)

769 Rudi Dornbusch, The New International Architecture, September 2002

770 Hans-Werner Sinn, Weber's Law and the Biological Evolution of Risk Preferences: The Selective Dominance of the Logarithmic Utility Function, September 2002

771 Thomas Mayer, The Macroeconomic Loss Function: A Critical Note, September 2002

772 Seppo Honkapohja and Kaushik Mitra, Learning Stability in Economies with Heterogenous Agents, September 2002

773 David Laidler, Inflation Targets Versus International Monetary Integration - A Canadian Perspective, September 2002

774 Morten I. Lau, Panu Poutvaara, and Andreas Wagener, The Dynamic Cost of the Draft, September 2002

775 Steven Brakman, Harry Garretsen, and Charles van Marrewijk, Locational Competition and Agglomeration: The Role of Government Spending, September 2002

776 Anke S. Kessler and Christoph Lülfesmann, The Theory of Human Capital Revisited: On the Interaction of General and Specific Investments, September 2002

777 Kjell Erik Lommerud, Frode Meland and Lars Sørgard, Unionized Oligopoly, Trade Liberalization and Location Choice, September 2002

778 Antonio Merlo and François Ortalo-Magné, Bargaining over Residential Real Estate: Evidence from England, September 2002

$779 \mathrm{Yu}-\mathrm{Fu}$ Chen and Michael Funke, Exchange Rate Uncertainty and Labour Market Adjustment under Fixed and Flexible Exchange Rates, September 2002

780 Michael S. Michael, International Migration, Income Taxes and Transfers: A Welfare Analysis, September 2002

781 Clemens Fuest and Alfons Weichenrieder, Tax Competition and Profit Shifting: On the Relationship between Personal and Corporate Tax Rates, October 2002

782 Jan Bouckaert and Hans Degryse, Softening Competition by Enhancing Entry: An Example from the Banking Industry, October 2002

783 Johann K. Brunner and Susanne Pech, Adverse Selection in the Annuity Market with Sequential and Simultaneous Insurance Demand, October 2002

784 Gregory D. Hess and Eduard Pelz, The Economic Welfare Cost of Conflict: An Empirical Assessment, October 2002 
785 Jan Erik Askildsen, Uwe Jirjahn, and Stephen C. Smith, Works Councils and Environmental Investment: Theory and Evidence from German Panel Data, October 2002

786 Geir H. Bjønnes, Dagfinn Rime, and Haakon O. Aa. Solheim, Volume and Volatility in the FX-Market: Does it matter who you are?, October 2002

787 John Evans and John Fingleton, Entry Regulation and the Influence of an Incumbent Special Interest Group, October 2002

788 Wolfgang Ochel, International Comparisons and Transfer of Labour Market Institutions, October 2002

789 B. Gabriela Mundaca, Moral Hazard Effects of Bailing out under Asymmetric Information, October 2002

790 Gene M. Grossman and Edwin L.-C. Lai, International Protection of Intellectual Property, October 2002

791 John Hassler, José V. Rodriguez Mora, Kjetil Storesletten, and Fabrizio Zilibotti, A Positive Theory of Geographic Mobility and Social Insurance, October 2002

792 Paul De Grauwe and Marianna Grimaldi, The Exchange Rate in a Model with Heterogeneous Agents and Transactions Costs, October 2002

793 Guido Friebel and Mariassunta Giannetti, Fighting for Talent: Risk-shifting, Corporate Volatility, and Organizational Change, October 2002

794 Jan Erik Askildsen, Badi H. Baltagi, and Tor Helge Holmås, Will Increased Wages Reduce Shortage of Nurses? A Panel Data Analysis of Nurses' Labour Supply, October 2002

795 Marko Köthenbürger and Panu Poutvaara, Social Security Reform and Intergenerational Trade: Is there Scope for a Pareto-Improvement?, October 2002

796 Paul De Grauwe and Laura Rinaldi, A Model of the Card Payment System and the Interchange Fee, October 2002

797 Volker Böhm and Tomoo Kikuchi, Dynamics of Endogenous Business Cycles and Exchange Rate Volatility, October 2002

798 Mariam Camarero, Javier Ordóñez, and Cecilio Tamarit, The Euro-Dollar Exchange Rate: Is it Fundamental?, October 2002

799 Misa Tanaka, How Do Bank Capital and Capital Adequacy Regulation Affect the Monetary Transmission Mechanism?, October 2002

800 Jörg Baten and Andrea Wagner, Autarchy, Market Disintegration, and Health: The Mortality and Nutritional Crisis in Nazi Germany, 1933-1937, October 2002 
801 Saku Aura, Uncommitted Couples: Some Efficiency and Policy Implications of Marital Bargaining, October 2002

802 Wolfram F. Richter, Delaying Integration of Immigrant Labor for the Purpose of Taxation, October 2002

803 Gil S. Epstein and Shmuel Nitzan, The Politics of Randomness, October 2002

804 John Hassler and José V. Rodriguez Mora, Should UI Benefits Really Fall over Time?, October 2002

805 Friedrich Breyer and Stefan Felder, The Dead-anyway Effect Revis(it)ed, October 2002

806 Assar Lindbeck and Solveig Wikström, E-exchange and the Boundary between Households and Organizations, November 2002

807 Dieter Bös, Contests Among Bureaucrats, November 2002

808 Steven Brakman, Harry Garretsen, and Marc Schramm, The Strategic Bombing of German Cities during World War II and its Impact on City Growth, November 2002

809 Florian Englmaier and Achim Wambach, Contracts and Inequity Aversion, November 2002

810 Sarbajit Sengupta, Delegating Recruitment under Asymmetric Information, December 2002

811 Rajshri Jayaraman, On the Partial Public Provision of a Private Good, December 2002

812 Stéphanie Stolz, Banking Supervision in Integrated Financial Markets: Implications for the EU, December 2002

813 Christian Keuschnigg, Taxation of a Venture Capitalist with a Portfolio of Firms, December 2002

814 Inés Macho-Stadler and David Pérez-Castrillo, Settlement in Tax Evasion Prosecution, December 2002

815 Rainer Niemann and Dirk Simons, Costs, Benefits, and Tax-induced Distortions of Stock Option Plans, December 2002

816 Jan-Egbert Sturm and Barry Williams, Deregulation, Entry of Foreign Banks and Bank Efficiency in Australia, December 2002

817 V. Anton Muscatelli, Patrizio Tirelli, and Carmine Trecroci, Monetary and Fiscal Policy Interactions over the Cycle: Some Empirical Evidence, December 2002

818 Claude Hillinger, A General Theory of Price and Quantity Aggregation and Welfare Measurement, December 2002 
819 Erkki Koskela and Ronnie Schöb, Optimal Capital Taxation in Economies with Unionised and Competitive Labour Markets, December 2002

820 Sheilagh Ogilvie, Guilds, Efficiency, and Social Capital: Evidence from German ProtoIndustry, December 2002

821 Hans Gersbach and Verena Liessem, Financing Democracy, December 2002

822 Costas Hadjiyiannis, Panos Hatzipanayotou, and Michael S. Michael, Optimal Tax Policies with Private-Public Clean-Up, Cross-Border Pollution and Capital Mobility, December 2002

823 François Ortalo-Magné and Sven Rady, Homeownership: Low Household Mobility, Volatile Housing Prices, High Income Dispersion, December 2002

824 Syed M. Ahsan and Panagiotis Tsigaris, Measuring the Social Discount Rate under Uncertainty: A Methodology and Application, December 2002

825 Kai A. Konrad, Altruism and Envy in Contests: An Evolutionarily Stable Symbiosis, December 2002

826 Robert S. Chirinko and Huntley Schaller, A Revealed Preference Approach to Understanding Corporate Governance Problems: Evidence from Canada, December 2002

827 Geir B. Asheim, Green National Accounting for Welfare and Sustainability: A Taxonomy of Assumptions and Results, December 2002

828 Andrea Gebauer, Chang Woon Nam, and Rüdiger Parsche, Lessons of the 1999 Abolition of Intra-EU Duty Free Sales for Eastern European EU Candidates, December 2002

829 Giacomo Corneo, Work and Television, December 2002

830 Vivek H. Dehejia and Yiagadeesen Samy, Trade and Labour Standards - Theory, New Empirical Evidence, and Policy Implications, December 2002

831 Geir B. Asheim and Wolfgang Buchholz, A General Approach to Welfare Measurement through National Income Accounting, December 2002

832 Aaron Tornell and Frank Westermann, The Credit Channel in Middle Income Countries, January 2002

833 Gebhard Flaig, Time Series Properties of the German Monthly Production Index, January 2002 